\title{
Hacerse cargo del pasado. Aproximaciones al problema de la responsabilidad en el debate No Matar
}

\section{Taking charge of the past. Approaches towards the problem of responsibility in No Matar debate}

\author{
Lucas Gerardo Saporosi \\ lucas.saporosi@gmail.com \\ Universidad de Buenos Aires \\ Universidad Nacional de La Plata \\ CONICET, Argentina
}

Recepción: 17 Abril 2020

Aprobación: 31 Julio 2020

Publicación: 01 Septiembre 2021

Cita sugerida: Saporosi, L. G. (2021). Hacerse cargo del pasado. Aproximaciones al problema de la responsabilidad en el debate No Matar. Sociohistórica, 48, e144. https://doi.org/10.24215/18521606e144

\begin{abstract}
Resumen: El artículo analiza el problema de la responsabilidad de las experiencias políticas de los años sesenta y setenta en Argentina a partir de un conjunto de intervenciones realizadas por exmilitantes en el marco del debate No matar. Específicamente, propone tres aproximaciones al problema que surgen de una serie de enfoques sobre la responsabilidad y que pueden resumirse en: a) la responsabilidad como falta políticomoral; b) la responsabilidad como balance político militante y c) la responsabilidad reflexiva. En este marco, nos preguntamos por las formas en que ha asumido la responsabilidad en las cartas de estos/as exmilitantes, y, extensivamente, por quiénes, de qué y ante quién se es responsable
\end{abstract}

Palabras clave: Responsabilidad, Memoria, Política, Militancia.

Abstract: The article analyzes the problem of responsibility regarding the 60's and 70's political experiences in Argentina and considering a series of memorial interventions of ex- militant actors and linked to No matar debate. Specifically, we propose three approaches to the problem which can be summarized as: a) a responsibility as a political-moral fault; b) a responsibility as a political-militant balance, and c) a reflective or bearing responsibility. To do so, we question the different ways in which responsibility has been assumed, and, extensively, who, from what and before whom they are responsible for.

Keywords: Responsibility, Memory, Politics, Militancy.

\section{INTRODUCCIóN}

Desde 1983, la pregunta por cómo abordar el accionar de las militancias durante el proceso de insurgencia y radicalización política de los años sesenta y setenta en Argentina ha estado ineludiblemente asociado al problema de la responsabilidad de aquellas acciones. Desde entonces, se ha tratado de una discusión fuertemente condicionada por las transformaciones sociohistóricas de la posdictadura y por la correlación de fuerzas políticas que han contribuido a delimitar los límites de lo decible y lo audible respecto a las disputas por los sentidos de memoria, verdad y justicia.

Durante la década del ochenta y los primeros años de la del noventa, se establecieron las condiciones de posibilidad para que ciertos/as exmilitantes de las organizaciones políticas construyesen una mirada crítica sobre su accionar, pero, como ha sugerido Emilio de Ípola, ese cuestionamiento se desarrolló de manera 
"fragmentaria e insuficiente" durante los primeros momentos de la democracia (1997, p. 24). Entre estos primeros ejercicios de memoria, se pueden citar un conjunto de reflexiones autocríticas orientadas por un posicionamiento crítico y condenatorio sobre la experiencia político-militante de los años anteriores (Giussani, 1984; Brocato, 1985; Terán, 1991; entre otros). Estas producciones, sumadas a una serie de ensayos político-intelectuales (Hilb y Lutzky, 1984; Ollier, 1986; Sigal y Verón, 1986, entre otros), contribuyeron a consolidar los discursos y sentidos de la "estrategia democrática" (Oberti y Pittaluga, 2006) y del "esquema binario de responsabilidades" (Franco, 2015), canonizados en el espíritu de la CONADEP, del Nunca Más y del Juicio a las Juntas. Fundamentada en el objetivo de juzgar a los represores militares y condenar el plan sistemático de exterminio, y con él toda forma de autoritarismo, la estrategia democrática implicó una necesaria despolitización de las víctimas de la represión durante la primera parte de los años ochenta, lo que obturó las diversas trayectorias de militancia y las adhesiones políticas (Crenzel, 2008).

Durante los años noventa, con la aparición de los nuevos movimientos sociales y el desarrollo de sus acciones de resistencia frente al "nuevo orden liberal" (Svampa, 2005; Retamozo, 2011), se comenzaron a recuperar las historias de militancias de quienes tensionaron las estructuras de la democracia representativa y asumieron el compromiso de construir otros proyectos políticos con horizontes de igualdad y bienestar social (Pittaluga, 2007). La emergencia de la agrupación H.I.J.O.S fue fundamental en este proceso y contribuyó a que cobraran mayor visibilidad una serie de ejercicios de memoria, escrituras testimoniales y producciones culturales orientadas a configurar una forma de la responsabilidad asociada a su condición de "balance político-militante". Se asociaban a ellas un conjunto de figuras y léxicos pertenecientes al universo militante y a las teorías revolucionarias de aquellos años, y se explicitaban discursos críticos a ciertas decisiones de las conducciones nacionales por la "desviación militarista" o la profundización del foquismo. Estas memorias militantes permitieron revisar las premisas de las autocríticas condenatorias propias de los años ochenta y de los primeros noventa.

Hacia fines de los noventa y durante los dos mil, una nueva forma de comprender la responsabilidad y el accionar militante irrumpió en los debates públicos. Desde nuestra perspectiva, una responsabilidad reflexiva se fue configurando a partir de la aparición de un conjunto de testimonios de mujeres militantes y sobrevivientes (Diana, 1996; Ciollaro, 1999; Actis, Aldini, Gardella, Lewin y Tokar, 2001), del debate No Matar (AAVV, 2007) y de los ejercicios de memoria de Pilar Calveiro (1998; 2005), entre otros. Estos ejercicios reflexivos habilitaron una revisión profunda e integral de la experiencia de los años sesenta y setenta, que permitió incorporar las voces y memorias de y sobre los/as sobrevivientes de aquel período, no solo a través de la recuperación de sus adscripciones políticas, sino también con la puesta en tensión de cuestiones de la vida cotidiana en la militancia, de los afectos y del rol de las mujeres. Si bien estas discusiones estuvieron presentes en períodos anteriores, este modo reflexivo de concebir el accionar y la responsabilidad de las militancias apareció con mayor fuerza en el período enmarcado por la crisis del 2001 y por el impulso a las políticas de memoria durante los gobiernos de Néstor Kirchner y Cristina Fernández de Kirchner. ${ }^{1}$

El contexto político de los últimos años ha revitalizado la vigencia pública y el carácter conflictivo de este debate. A partir del año 2008, y sobre todo a partir del ascenso al gobierno de la Alianza Cambiemos, han reaparecido con mayor fuerza una serie de representaciones y discursos sociales asociados a la reconciliación, a la teoría de los dos demonios, al negacionismo y/o al perdón, propios de las demandas históricas de las agrupaciones y espacios cercanos a los represores y a la corporación militar (Bertoia, 2016; Feierstein, 2018; Godoy y Barbero, 2016). También, en ese entramado se comenzó a constituir públicamente una figura emergente, la del "diálogo" (Saferstein y Goldentul, 2019), en cuya narrativa han coexistido nuevas y antiguas representaciones en torno a la responsabilidad y el accionar de las militancias. ${ }^{2}$ 


\section{El debate No Matar. Sobre la responsabilidad. Contextualización y modo de} ABORDAJE

Entre las intervenciones intelectuales que mayormente pusieron el foco sobre el interrogante de la responsabilidad de las militancias, el debate No Matar se ha constituido como una referencia ineludible. Esta controversia surgió de la publicación de una serie de extractos pertenecientes a una entrevista realizada a Héctor Jouvé para el documental La guerrilla que no fue por la revista La Intemperie a fines del año 2004. En su testimonio, Jouvé, quien fuera militante del Ejército Guerrillero del Pueblo (EGP) ${ }^{3}$ durante los años sesenta, aludió a su experiencia en el monte salteño y narró sus vivencias cotidianas, sus percepciones sobre la práctica guerrillera y ciertas acciones de intervención violenta sobre las subjetividades militantes. En particular, mencionó fusilamientos y ejecuciones desarrolladas contra miembros de la guerrilla del EGP. Si bien el testimonio se extendió por otras derivas políticas y personales, estas alusiones fueron las que motivaron la carta de Oscar del Barco, cuya publicación dio inicio a un intenso debate entre intelectuales, exmilitantes políticos y académicos -casi en su totalidad varones y con una reconocida trayectoria en el campo intelectual-. La discusión trascendió el espacio de la revista La Intemperie y generó una serie de intervenciones académicas e intelectuales desde diferentes posicionamientos, vinculadas al cruce entre violencia, política y responsabilidad, que culminaron en la publicación de dos volúmenes (2007).

El debate ha sido objeto de estudio de una diversidad de trabajos académicos e intelectuales durante los últimos años. Algunos de ellos fueron editados en el segundo tomo de la publicación y se orientaron a abordar el asunto desde diversas perspectivas. Entre estas, Victoria Basualdo (2006) analizó el modo en que la controversia permitió ampliar la agenda de investigación en el campo de estudios; Tarcus (2006) realizó una reflexión político-intelectual sobre el rol de las izquierdas en relación a la lucha armada e intervino en un contrapunto con Elías Palti (2008) en relación a la premisa de "no matarás" y la violencia revolucionaria. En los últimos años, Graciana Vázquez Villanueva (2017), desde una perspectiva basada en el análisis del discurso, revisitó la problemática en cuestión, a través de un riguroso trabajo de análisis de dos de las cartas más relevantes del debate, la de Oscar del Barco (2004) y la de Héctor Schmucler (2005)

A partir de la perspectiva interdisciplinaria del campo de estudios de la memoria, el presente artículo busca analizar específicamente el problema de la responsabilidad a partir de un conjunto de intervenciones realizadas por exmilitantes en el marco del debate No matar. El trabajo propone tres aproximaciones al problema, tomando en consideración las cartas de Oscar del Barco (2005), Eugenio Castillo (2005), Héctor Schmucler (2005) y el artículo de Claudia Hilb [2005] (2014). Estas aproximaciones surgen y son parte de una serie de enfoques sobre la responsabilidad, construidos en el marco de una investigación más extensa, y que pueden resumirse de la siguiente manera: a) la responsabilidad como falta político-moral; b) la responsabilidad como balance político militante, y c) la responsabilidad reflexiva ${ }^{4}$. En este marco, nos preguntamos por las formas en que ha asumido la responsabilidad en las cartas de estos/as exmilitantes respecto a su participación política durante los años sesenta y setenta, y, extensivamente, nos interrogamos por quiénes, de qué y ante quién se es responsable.

Comprendemos a estas intervenciones como "ejercicios críticos de memoria" (Oberti y Pittaluga, 2006) que ponen en evidencia la condición de "trabajo" de dicho proceso (Jelin, 2002) en la medida en que constituyen una forma de respuesta frente a las experiencias de dolor y/o de violencia. Por tanto, uno de los aspectos fundamentales del abordaje atiende al modo en que los/as enunciadores de estas cartas construyen sus ejercicios de memoria en un doble movimiento:, por un lado, conjugan la dimensión político-intelectual sobre la experiencia militante de aquellos años, y, por el otro, la autorreferencialidad de una primera persona que se hace responsable y que elabora los sentidos de la experiencia del pasado en el presente.

Por último, comprendemos al debate como un "vector de memoria" (Rousso, 2007), a partir del cual emerge el problema de la responsabilidad como discusión relevante en la esfera pública y condiciona los "marcos sociales de la memoria" (Halbwachs, 2005). En este sentido, se inscribe en la tradición de los debates 
intelectuales latinoamericanos, como los ha analizado Claudia Gilman (2003), y como parte de una "cultura del discurso crítico" (Gouldner, 1979), en la cual las posiciones de enunciación de los/as intelectuales se entrelazan en el marco de una producción de sentidos críticos sobre distintas dimensiones de las sociedades latinoamericanas.

\section{Primera aproximación: La Responsabilidad como Falta político-Moral}

\subsection{La conmoción de Oscar del Barco y el inicio de la polémica}

La figura de Oscar del Barco es una figura central en el campo intelectual argentino. Durante los primeros años de la década del sesenta, estuvo vinculado al Partido Comunista en la ciudad de Córdoba y su formación político-intelectual se desarrolló dentro de la tradición marxista. En 1963, junto a Héctor Schmucler, José Aricó y Samuel Kiczkovsky fundaron la emblemática revista Pasado y Presente, y, ese mismo año, tomaron contacto con el Ejército Guerrillero del Pueblo (EGP) 5 . El vínculo con el EGP es crucial para comprender la genealogía de la discusión y el modo en que la carta de del Barco permite establecer las coordenadas a partir de las cuales se desarrollará la controversia.

Ante el testimonio de Jouvé, Oscar del Barco responde con una interpelación ético-política, intensamente afectiva, hacia la generación política de la que él ha sido parte y a la que hace un llamamiento a "hacerse cargo" de sus acciones durante los años de radicalización política.

\footnotetext{
Al leer la entrevista con Héctor Jouvé, cuya transcripción ustedes publican en los dos últimos números de La Intemperie, sentí algo que me conmovió, como si no hubiera transcurrido el tiempo, haciéndome tomar conciencia (muy tarde, es cierto) de la gravedad trágica de lo ocurrido durante la breve experiencia del movimiento que se autodenominó "ejército guerrillero del pueblo”. Al leer cómo Jouvé relata sucinta y claramente el asesinato de Adolfo Rotblat (al que llamaban Pupi) y de Bernardo Groswald, tuve la sensación de que habían matado a mi hijo y que quien lloraba preguntando por qué, cómo y dónde lo habían matado, era yo mismo (del Barco, 2004, p. 35, en AAVV, 2007).
}

La conmoción del enunciador pone en evidencia una marca profunda de su experiencia política durante los años sesenta. Y, al hacerla pública, interpela, por un lado, al director de la revista, Sergio Schmucler, y, por el otro, a ese "nosotros generacional", que incluye no solo a quienes participaron de aquel episodio específico del EGP, sino también a quienes intervinieron, en mayor o en menor medida, de las distintas experiencias militantes de los años sesenta y setenta, y que optaron por las distintas formas de la lucha armada. ${ }^{6}$ Pero, ante todo, esa conmoción le permite asumir una responsabilidad ante otros, ante "el absolutamente otro", que puede traducirse ante "los otros hombres", o bien, ante "posible Dios" (p. 36). El ethos conmocionado, como postura y palabra, constituye el modo en que el enunciador responde ante ese otro inabarcable, pero con quien mantiene lazos solidarios de comunidad. Asimismo, como veremos a continuación, su intervención puede asociarse a una forma de la responsabilidad comprendida como una falta político-moral. ${ }^{8}$

\subsection{La responsabilidad, entre la crítica al ideal político y la condena al ejercicio de violencia. La recuperación de Claudia Hilb}

Claudia Hilb recupera la conmoción de la carta del filósofo cordobés y su reflexión, como ella misma sugiere, "se inscribe de manera oblicua en el debate abierto por la carta de Oscar del Barco" (Hilb, [2005] 2014, p. 11), en tanto no formó parte de la revista La intemperie ni de aquellas por donde continuó el debate. Asimismo, se presenta como un texto que no pertenece al formato epistolar, sino que se organiza como un artículo intelectual de carácter autorreferencial. "Moldeando la arcilla humana: reflexiones sobre 
la igualdad y la revolución" fue una ponencia presentada al Encuentro Internacional Política y Violencia, en la ciudad de Córdoba en noviembre 2005 y luego publicada en un libro compilado por Héctor Schmucler en el 2007. ${ }^{9}$

El recorrido de la autora en el mundo de la militancia política en los años setenta se inició dentro del Frente Argentino de Liberación (FAL) en la Facultad de Derecho, una agrupación estudiantil de izquierda que confluyó en el Partido Revolucionario de los Trabajadores. Su experiencia militante se sostuvo hasta abril de 1976 cuando se exilió en Francia. Desde 1984, ha tenido un prolífico desarrollo intelectual y ha sido una de las autoras más activas en el campo de estudios sobre la memoria y el pasado reciente. Ya en $L a$ nueva izquierda argentina, 1960-1980 (1984), texto coescrito con Daniel Lutzky, la perspectiva de la autora explicitó con claridad su posicionamiento crítico frente a las experiencias políticas y militantes de los años setenta, posicionamiento que mantuvo a lo largo de su trayectoria, pero que fue articulándose de distinta manera con el proceso histórico de memoria, verdad y justicia en la posdictadura. En el año 2001 publicó "El legado de responsabilidad" en la revista Puentes de la memoria y revitalizó aquella crítica con interés de problematizar el vínculo entre política y violencia, y subrayar la importancia de atender a la responsabilidad dentro de ese cruce.

Claudia Hilb, en tanto exmilitante, recupera la pregunta por la responsabilidad refiriéndose, en primer lugar, a quién debe hacerse cargo, y trazando una frontera entre los diferentes sujetos históricos que la impulsan:

La polémica desatada por la carta de Oscar del Barco ha reafirmado algo que, en realidad, ya sabíamos: una nítida línea divisoria separa entre quienes hemos sido de diversas maneras y en diversos grados partícipes de la violencia política en los años sesenta y los setenta, a aquellos que consideramos que debemos asumir una responsabilidad por el destino terrible de esa experiencia, por las muertes a las que condujo, de aquellos que consideran que fueron, simplemente, las víctimas injustas de una guerra justa y que sólo les cabe reflexionar acerca del porqué de lo que consideran una derrota, derrota de ellos mismos y del campo popular, por supuesto (p. 43).

Hilb se posiciona a un lado de esa línea y delimita con claridad el "nosotros" de esa interpelación: "aquellos quienes hemos sido partícipes de la violencia política”; una alusión en primera persona que se traduce, nuevamente, en clave generacional y remite a un conjunto de militantes de las organizaciones políticas de aquellos años. Pero, además, en la delimitación de esa frontera, la enunciadora refiere a que "quienes consideramos que debemos asumir una responsabilidad por el destino terrible de esa experiencia no solemos creer que esa experiencia deba pensarse en los términos de una derrota" (p. 44 [itálicas propias]). De modo que en la construcción de ese nosotros se le otorga una dimensión de carácter moral -un "debemos"- al acto de hacerse cargo. Esto implica que, al momento del decir y hacer pública la asunción de responsabilidad, se deberian cuestionar las prácticas que se desarrollaron y los ideales que se enarbolaron por haber conducido a la muerte y al "destino terrible".

Este planteo puede vincularse con la lectura de Paul Ricoeur (1997) en torno al problema semántico de la responsabilidad y su acepción clásica del término. Según el autor:

el concepto jurídico clásico que asocia la noción de responsabilidad con la obligación de reparar un daño causado (derecho civil) o de soportar un castigo (derecho penal), ha contribuido a la fuerte asociación que existe entre responsabilidad, reprobación, falta, reparación y castigo (p. 39).

Siguiendo a Ricoeur, el fundamento jurídico clásico de la responsabilidad, al asociarse con la obligación a reparar un daño o soportar un castigo, inevitablemente contribuyó a ligar el concepto con el sentido moral de la imputación, entendida como la forma de "atribuir a alguien un acto culpable, una falta, y por ende, un acto reñido de antemano, con una obligación o una prohibición que dicho acto enfrenta” (1997, p. 41). Este movimiento conceptual permitió que el modelo clásico de la responsabilidad-obligación se inscribiera en la tradición de la filosofía moral, a través de la idea de retribución. Así quedó conformado el trinomio clásico: responsabilidad-imputación-retribución. Lo relevante aquí es subrayar que cuando la pregunta por la 
responsabilidad de las acciones se realiza bajo el criterio de una falta, inevitablemente queda también asociada a la acción de imputación, que puede asumirse de manera individual o colectiva.

Pero, en el caso de Hilb, la responsabilidad que ilumina la carta de del Barco no refiere únicamente a la cuestión moral, sino que también considera la dimensión política en su planteo; la de hacerse responsables por "haber querido un bien que, de la manera en que lo concebíamos, hoy creemos que sólo podía conducir al mal" (p. 44). El "bien" sobre el que argumenta esta responsabilidad se asienta sobre un principio de igualdad que los mismos procesos revolucionarios que lo encarnaron durante la historia del siglo XX, según Hilb, lo materializaron imponiendo un régimen totalitario y de terror (p. 47). Particularmente, centra su atención en la construcción de la sociedad cubana pos revolucionaria y en el ideario del hombre nuevo. Así, sostiene que aquella anhelada igualdad tuvo un destino trágico que solo pudo desarrollarse bajo la peor forma política moderna. En este sentido, las subjetividades militantes, "moldeadas" o "capturadas" por los partidos revolucionarios, orientaron sus acciones según un principio de igualdad cuya forma política fue la del totalitarismo y la de sus mecanismos de operación: la coerción y el miedo. ${ }^{10}$ Afirma:

¿Qué habría sido de nosotros, de nuestras vidas y de nuestros valores en el caso de que no hubiéramos sido derrotados, en el caso de que las organizaciones de las que formábamos parte o a las que apoyábamos hubieran triunfado? (...) ¿Qué habría sido de nosotros, vuelvo a preguntarme, si aquella revolución que anhelábamos se hubiera realizado? (pp. 45-46).

En este sentido, el ethos cuestionador que construye la enunciadora está delimitado por su condena a ese ideal pretérito asociado a una concepción determinada de la revolución y de la violencia. En este sentido, podemos inscribir a esta forma de asumir la responsabilidad como una falta político-moral, dado que contribuye a revisar aquella experiencia militante de manera cuestionadora en su totalidad, desde lo que fue su condición utópica (la realización revolucionaria), pasando por sus elementos simbólicos y morales (la configuración de una nueva subjetividad), hasta sus prácticas, roles y percepciones sobre cómo proseguir y alcanzar aquel ideal político.

Este cuestionamiento político y moral anuda en su reflexión un núcleo fundamental de largo aliento en la obra intelectual de Claudia Hilb: el vínculo teórico entre política y violencia a la hora de aproximarse a las experiencias militantes que optaron por el camino revolucionario. Este núcleo de la controversia pone en evidencia una importante discusión acerca del modo en que las organizaciones políticas asumieron la cuestión de "lo político" y su vínculo con las subjetividades militantes. En esa reflexión, suelen ponerse en entredicho los imaginarios revolucionarios, la efectiva capacidad de acción y decisión de las subjetividades y el modo de asumir -o no- las estrictas normas de comportamiento exigidas por las organizaciones. Para Hilb, ese nosotros generacional se configura a partir de una representación relativamente estable y homogénea de la "militancia revolucionaria", asociada directamente con las organizaciones político-militares (OPM) ${ }^{11}$ y caracterizada por un universo de sentidos delimitado por la figura del hombre nuevo y el ascetismo revolucionario.

Por último, resulta pertinente señalar que el ejercicio de memoria de Hilb le otorga un lugar de preeminencia al fundamento principal de la argumentación de del Barco, aquel que sostiene que el principio que funda toda comunidad es el principio del "no matarás". ${ }^{12}$ Este fundamento es el que condiciona la noción de responsabilidad que Hilb intenta destacar de aquella intervención inicial. La enunciadora no asocia el concepto de responsabilidad a la idea de culpa, vale aclararlo, pero sí refiere al universo de sentidos asociados a la falta, a la condena y a lidiar con una imputación social fundamentada en una demanda por repararlo, con el fin de contribuir a la restitución de la verdad.

Esta revitalización político-moral de la responsabilidad cobra también relevancia en la medida en que Hilb explicita su posicionamiento frente a las disputas de memoria, verdad y justicia durante los años dos mil. En este sentido, varios de sus planteos se han orientado a discutir ciertas premisas y orientaciones de las políticas de memoria impulsadas por la gestión de Néstor Kirchner, en especial, aquellas vinculadas a la reapertura de juicios por crímenes de lesa humanidad, en las cuales prevaleció, según su mirada, la voz y el discurso de 
los organismos de derechos humanos. ${ }^{13}$ Esta idea de una supuesta "memoria oficial", para usar el término de Vera Carnovale (2014), se tradujo en una falta de autocrítica por parte de la generación militante respecto de un conjunto de ideales, mandatos y acciones políticas desarrolladas en nombre de una sociedad igualitaria que contribuyó a consolidar una concepción antipolítica de aquellos valores originarios de justicia, libertad e igualdad.

\section{SEgUNDA APROXIMACIÓN: LA RESPONSABILIDAD COMO BALANCE POLÍTICO-MILITANTE}

En el marco del debate $\mathrm{N}$ matar, la carta de Eugenio Castillo (2005) puede articularse con ese conjunto de ejercicios de memoria y testimonios surgidos hacia finales de los años ochenta, pero extendidos durante la segunda parte de la década del noventa, y enmarcados en las revisiones críticas, que tomaron la forma de balances político-militantes. ${ }^{14}$

La epístola de Eugenio Castillo, quien fuera militante de la Juventud Universitaria Peronista en la ciudad de Rosario durante los años 1973 y 1976, apela a un doble destinatario. Por un lado, interpela al director de la revista La intemperie, Sergio Schmucler:

Señor director, la revista que usted dirige abrió una caja de Pandora. El problema es saber qué hacemos con lo que salió de ella. Porque si es solamente para quedarnos sentados hablando de lo malo que fuimos, disfrutando el amargo arrepentimiento, creo que no sirvió para nada. Pensando eso, escribí la siguiente carta que espero sea digna de publicación (Castillo, 2005, p. 123, en AAVV, 2007).

Bajo este apelativo inicial explicita un tono imperativo frente a la serie de cartas que precedieron a la suya. Pero, además, adelanta un claro posicionamiento frente al objeto de la disputa, diferente al de las posturas enunciativas de del Barco y de Claudia Hilb. Castillo considera la irrupción del debate como la apertura de una "caja de Pandora", subrayando, por un lado, que el tema central de la controversia se encontraba en un estado de invisibilidad o desplazado de una superficie de discusión, y, por el otro, señalando el carácter mismo de la aparición, como un acto de irrupción que provoca una interpelación ineludible. En este sentido, el autor postula que su carta se hará cargo de esta irrupción, pero desde un posicionamiento que no "disfrute del amargo arrepentimiento" (Castillo, 2005, p. 123, en AAVV, 2007).

La segunda interpelación refiere al conjunto de "intelectuales" que participan abiertamente de la polémica. El enunciador lo afirma en el subtítulo de su carta: "Carta a los intelectuales que ya no creen en las revoluciones o: matar o no matar, ¿esa es la cuestión?”

Hacer alusión a los "intelectuales" sin referir a su condición de exmilitantes y/o sobrevivientes -condición identitaria de buena parte de los sujetos enunciadores del debate- ya constituye una toma de posición en la polémica y una caracterización acerca de los polemistas. En este sentido, tomando en consideración una serie de trabajos e investigaciones académicas sobre las experiencias de militancia de los años sesenta y setenta, ${ }^{15}$ resulta pertinente señalar que la figura del "intelectual comprometido" era considerada parte del universo de la militancia, de modo que la apelación de Castillo pretende distinguirla de un "nosotros" militante e interpelar a esos "ustedes" (también militantes y sobrevivientes de la represión estatal), que han devenido intelectuales "que ya no creen en las revoluciones" (p. 123). El enunciador pareciera aludir críticamente a las transformaciones en el campo intelectual de principios de los años ochenta, que, impulsadas por las autocríticas y la "estrategia democrática", tendieron a revisar y desanudar ese fuerte vínculo entre las esferas militantes e intelectuales y, en consecuencia, a configurar un distanciamiento entre los ideales de cambio social del pasado y los actuales.

En este marco, la carta de Castillo constituye una clara toma de posición en la polémica: "Soy culpable. Salvo excepciones, aplaudí los llamados ajusticiamientos hechos por los Montos y en general todas sus acciones "fuera de la ley" (secuestros, robos, etc.)" (p. 123). 
La cita ubica a un enunciador autorreferencial que se asume culpable de una serie de acciones cometidas por la organización política Montoneros, referida como los montos. ${ }^{16}$ Por eso, al referirse como tal, el enunciador no solo está evidenciando una adscripción política, sino también un léxico compartido durante los años de militancia. Este rasgo discursivo responde a un universo de sentidos propio de aquella experiencia y constituye parte del intertexto de la carta. En efecto, la marca que subraya, por ejemplo, "los llamados ajusticiamientos", se orienta en una dirección que inscribe al enunciador como conocedor de ese lenguaje y como parte de una genealogía política más extensa.

Dice el enunciador:

Usábamos la palabra ajusticiamiento porque nos sentíamos protegidos de una legalidad diferente: antes de "ajusticiar" siempre hacíamos un "juicio popular”, cuyas reglas eran distintas a los juicios normales: no había jueces, ni defensores. Es decir, que actuábamos en base a un Derecho y un Código que emanaba de sentirnos representantes del "sentir popular", o de un sentir "objetivamente" popular (p. 124).

Las comillas, las cursivas y las mayúsculas corresponden al texto original y tienen la función de insertar el ethos del enunciador en el intertexto referido a todo un entramado de producciones teóricas y políticas latinoamericanas sobre la revolución y la lucha armada, el foquismo, la guerra popular prolongada. Estas huellas constituyentes y fundantes de las experiencias políticas revolucionarias de aquellos años son operaciones de sentido tendientes a construir un sujeto enunciador que se presenta como portavoz de aquel universo, bajo un ethos militante, que no solo remite a la experiencia del pasado, sino que también constituye su identidad en la actualidad: "A pesar de mis arrepentimientos, soy de los que siguen pensando-actuandoluchando para cambiar el mundo” (p. 124). El ethos militante es la figura que el enunciador construye para interpelar a los otros enunciadores de la polémica. Con un tono imperativo y con un léxico militante, la carta de Castillo incorpora las premisas de sus polemistas en una clave que busca rebatir las posiciones críticas que revisaron los ideales políticos de transformación, sus prácticas y su universo de representaciones. En este caso, es un ethos que se asume culpable, pero cuya culpa no se anuncia como una falta o una condena, sino como una estrategia de la enunciación para reivindicar su postura.

Ante la pregunta por el objeto de esa responsabilidad, “¿de qué se hace responsable el enunciador?”, la respuesta se desplaza a un aspecto de la argumentación que intenta tensionar los preceptos abstractos y a históricos del ejercicio de la violencia:

Pero no quiero hablar de las aberraciones que se hicieron bajo ese esquema, lo que quiero es remarcar que, efectivamente aceptábamos que matar era una herramienta posible para transformar la sociedad. El tema es que, perdón, pero no le veo nada tan terrible al asunto (p. 124).

Por un lado, el enunciador menciona las “aberraciones" realizadas en nombre de esa legalidad revolucionaria (el Código de Justicia Revolucionario de Montoneros), pero desplaza esa consideración hacia el final de su carta. Privilegia, en cambio, que "matar era una herramienta posible para transformar la sociedad" y le quita el peso moral y religioso que los polemistas precedentes le otorgaron a la cuestión de la violencia en sus diatribas. ${ }^{17}$ Precisamente, lo que intenta presentar es un vínculo entre violencia y política diferente al postulado por Hilb y del Barco. Afirma: "No veo que el asunto 'matar o no matar' sea decisivo para objetar las ideas que quisieron o quieren todavía intentar torcer el rumbo y construir otra opción” (p. 125).

Podemos decir que un primer aspecto de esta forma de asumir la responsabilidad contempla el vínculo entre la política y la violencia como una relación que no es mutuamente excluyente. En efecto, existen múltiples imbricaciones entre ambas esferas, en tanto responden al modo en que los sujetos leen y se posicionan frente a los condicionamientos históricos y sociales de un determinado momento. Los procesos de insurgencia y radicalización de los años sesenta y setenta lo evidencian, como sugiere el enunciador: "No sólo las revoluciones matan (...) también la no violencia mata” (p. 125). En una clara reapropiación del precepto "no matarás" postulado por del Barco, la carta de Castillo intenta poner de relieve todas las otras formas de la violencia (la estructural, la simbólica, etc.) que, según el enunciador, se han naturalizado en el imperativo "no 
matarás" y en la figura del "hombre sagrado". En este sentido, el ethos militante evidencia que la política y la violencia construyen zonas legítimas de encuentro según el contexto específico y la correlación de fuerzas. ${ }^{18}$

Un segundo objeto de esta responsabilidad apunta al reconocimiento de una serie de errores y malas lecturas políticas que desarrollaron las organizaciones y, específicamente, sus conducciones nacionales. La carta se inscribe en esta perspectiva y, en lugar de asumir una demanda obligatoria a hacerse cargo de un accionar militante reprobable, revitaliza una forma de hacerse responsable en clave de una respuesta político-militante. Esa respuesta se configura como una revisión que se despega del enfoque precedente y puede articularse con otro planteo de Ricoeur; aquel referido a la idea de la rendición de cuentas como una forma de la responsabilidad que prioriza la capacidad de dar respuesta. Resulta interesante destacar que esta conceptualización revitaliza el lugar de la acción en la responsabilidad por sobre la obligación retributiva o imputación y, a través de ella, privilegia en el análisis la condición de los sujetos a hacerse cargo de sus acciones, en el sentido que la entiende Manuel Cruz (2015).

Pero ante todo y para el caso de la carta de Castillo, la idea de balance no se desprende del universo moral que ha sugerido Ricoeur, sino del universo político y, específicamente, de la experiencia militante que trae a cuestas a la hora de dar cuenta de sus acciones frente a una demanda de transmisión y de memoria. ${ }^{19}$ En efecto, la forma que asume la noción de responsabilidad se fundamenta en una concepción que la sustrae del universo de la condena y de la imputación jurídica y social, y la incorpora en la constelación de sentidos de la acción política (Levín, 2007) y, más específicamente, de la acción político-militante. Dar respuesta a aquella demanda, efectivamente, implica revisar y explicitar críticamente el accionar violento, pero no situarlo en una argumentación abstracta, ahistórica ni religiosa. Por el contrario, remite, ante todo, a una contextualización y genealogía de las acciones de las militancias y de su rol en la resistencia contra las dictaduras y los dispositivos de represión estatal. Afirma el enunciador Castillo:

¿De esto se debe inferir que la muerte me es indiferente? No. ¿Que no me parecen aborrecibles los asesinatos de los dos fusilados por el EGP en Salta? Tampoco. ¿Que me congratulo, ahora, del asesinato de, por ejemplo, José Ignacio Rucci, hace treinta años? No. Lo que quiero decir es que considero el asesinato de Rucci o de los guerrilleros un error político, no ético (p. 126).

Así, el enunciador propone una polémica en la que el sujeto responsable responde en términos políticomilitantes y le otorga un sentido específico a esa acción de responder, capaz de evidenciar y ponderar errores y aciertos en el accionar revolucionario del pasado. Con este posicionamiento Castillo se orienta a intervenir en las disputas de memoria, verdad y justicia de aquellos años. Frente a ellas, contribuye a reinstalar en la escena de discusión la dimensión emancipatoria de los proyectos revolucionarios de los años sesenta y setenta y a ponderar su participación en ellos. Dice: "Simpaticé en mayor o menor medida con todas las acciones de todas las organizaciones rebeldes. (...) Me hago responsable de todas las acciones que grupos de seres humanos hayan realizado o estén realizando en nombre de un proyecto sensatamente emancipatorio" (pp. 123-124). Su responsabilidad reivindica la participación militante y tensiona las decisiones que motivaron la acción en el pasado, y que en el marco de un ejercicio de memoria se resignifican en tiempo presente, bajo nuevas condiciones sociales y políticas. Frente a ellas, el enunciador interpela a las militancias del presente, explicitando su legado sobre la experiencia política e intentando señalar las condiciones para contribuir a un debate más amplio por las formas de intervención y activación política en la actualidad.

\section{TERCERA APROXIMACIÓN: LA RESPONSABILIDAD REFLEXIVA}

La respuesta de Héctor Schmucler a la carta de Oscar del Barco lleva el nombre de "Los relámpagos iluminan la noche" y fue enviada a la revista en mayo de 2005. Su intervención forma parte de los inicios del debate y permite reconstruir una genealogía sobre la cuestión de la responsabilidad que se remonta a las discusiones intelectuales y políticas durante los años del exilio, particularmente en la revista Controversia, 
entre los años 1979 y 1981. El autor de la carta, amigo personal de Oscar del Barco y compañero en Pasado y Presente, también fue un activo intelectual comprometido con el proceso político de los años sesenta y setenta.

La pregunta “¿ante quién se hace responsable el enunciador de la carta?” reconoce, en primer lugar y siguiendo el registro del conjunto de cartas precedentes, al director de la revista, Sergio Schmucler. Héctor es el padre de Sergio y de Pablo, desaparecido durante la dictadura, condición que contribuye a que la epístola asuma una modalidad eminentemente afectiva, y que, sin correrse de una mirada crítica, comprenda el desarrollo de la polémica como un modo de interpelación entre pares, compañeros y amigos. En este sentido, el enunciador comienza su carta invocando a sus amigos-compañeros (Oscar del Barco, Nicolás Casullo y Alejandro Kaufman) a través de la construcción de una escena masculina de amistad. Señala:

Queridos Oscar, Nicolás, Alejandro, los relámpagos iluminan la noche. (...) Allí están las cartas de ustedes a las que ahora se agrega la mía. Hablan del mundo pero no vacilan en exponer nuestras intimidades; un gesto que privilegia la amistad sobre cualquier diferencia en el tratamiento de las ideas. No es sólo la convicción compartida de que las biografías importan como documento de fidelidad al pensamiento, sino que la vida, nuestras precisas vidas, han cruzado con más intensidad la experiencia de existir que la búsqueda de ordenadas especulaciones (Schmucler, 2005, p. 88, en AAVV, 2007).

En este caso, la escena enunciativa desdibuja uno de los límites centrales del género agónico o polémico, el de la distinción entre coenunciadores y polemistas. Héctor Schmucler admite que la presente carta ha formado parte de una serie de discusiones previas entre ese grupo de amigos y ha sido escrita en el marco de ese entrelazamiento, como si constituyese una coescritura caracterizada por un doble reconocimiento, afectivo (amigo) y político (compañero). En esta línea, el enunciador del Barco, referente fundacional de la controversia, tiende a dejar de ser un polemista y se incorpora como un coenunciador en esta escena de amistad.

La carta de Schmucler, en esta coenunciación, destaca la necesidad de producir una comprensión integral sobre las implicancias que reviste actuar con otros, contra otros y hacerse cargo de ello y, en ese sentido, no condena a del Barco por su carácter anacrónico o por el fundamento religioso del mandato "no matarás", sino que intenta recuperar su postura para encontrar la posibilidad de asumir la responsabilidad de la experiencia militante en una clave reflexiva.

El ethos reflexivo de la carta de Schmucler consiste en reponer las conmocionadas palabras de Del Barco en una profunda preocupación ético-política y generacional sobre el legado de sus acciones, desplazándose de ciertos relatos heroicos e imaginarios revolucionarios. Por el contrario, "ese relámpago estallado en medio de un cielo luminoso" -en referencia al modo en que incorpora la carta de su amigo/compañero Del Barco- precisamente busca recuperar sus otrora cualidades militantes, aquellas que implicaron críticas, distanciamientos, miedos, vacilaciones, dudas y contradicciones personales. Así, el enunciador Schmucler recupera, con el cuidado y la confianza de una amistad, sus marcas y "cicatrices" en la memoria de su generación (Schmucler, 2005, p. 88, en AAVV, 2007).

Por otro lado, la carta también pone en evidencia una serie de inquietudes de largo aliento de esta generación de militantes. El enunciador comprende la discusión como un intento de reflexionar conjuntamente sobre los acontecimientos que los conmocionaron en el pasado ante a una demanda generacional que, desde los años dos mil, ha resultado ineludible para el campo de las izquierdas. En esta línea, la polifonía de la carta recupera un universo compartido de lecturas y preocupaciones teórico-políticas, a través de alusiones a fragmentos literarios y a obras artísticas, como si constituyesen un código generacional en común. ${ }^{20}$ Estas marcas polifónicas contribuyen a definir esa coenunciación, y, por sobre todo, a construir el lazo entre ese nosotros generacional, orientado a transmitir aquella experiencia de manera crítica, reflexiva y atravesada por los acontecimientos. ${ }^{21}$ Por ello, ante la conmoción de las palabras de Del Barco, el ethos reflexivo las hace propias desde la contención de un amigo:

El peso de la muerte, de lo absurdo, de lo inmisericorde, del hundimiento en la nada, es el grito de Oscar desde un dolor inenarrable (¿quién, mis amigos, no ha sentido alguna vez que todo su cuerpo se transformaba en un dolor inenarrable?) que 
clama por ser escuchado, porque el grito contiene el silencio del asesinado, porque sus manos se han vuelto sospechosas de haber empuñado el arma que remató a quien podría haber sido su hijo (p. 95).

Como puede verse en este aspecto, el objeto de la responsabilidad alude explícitamente a las consecuencias por el ejercicio de la violencia y "por haber empuñado el arma". Este objeto que emerge como un grito, como un relámpago en la noche, es el nudo central del ya señalado vínculo entre la violencia y la política. En este caso, a diferencia de las posturas precedentes, la mirada del enunciador sobre esta cuestión sugiere una perspectiva a la vez crítica y compleja. Dice:

Así, amigos, fueron siempre nuestros encuentros: pensábamos la política desde la ética aunque el sistema (dentro del cual ahora reconocemos rostros familiares) se mofara de nuestra inadecuación con la época. La política siempre fue para nosotros una manera de pensar el mundo y por eso renegamos del saber como camino al poder. Habíamos puesto en cuestión, justamente, el poder, el sistema de dominación, porque veíamos que allí los hombres se volvían cosas. No sabíamos (y el no saberlo debería llamarnos al arrepentimiento) que trabajábamos para que todas las cosas (los hombres entre ellas) simplemente pasaran al servicio de otro poder (p. 93).

Esta aproximación permite entrever que la afirmación de pensar la política desde la dimensión ética contribuye a delinear un camino tendiente a complejizar el vínculo entre organizaciones políticas y subjetividades, y, extensivamente, entre violencia y política. Por un lado, nos permite considerar una noción de la política como una experiencia que atraviesa (y atravesó) todos los aspectos de sus vidas, aun en el contexto de radicalización y violencia. Esto da cuenta de que la experiencia militante de aquellos años, aun en un entorno de fuertes mandatos de las organizaciones políticas, se concibió como una experiencia política, en la cual la ética fue un componente activo en las acciones de las subjetividades. Pero, por el otro lado, nos advierte que, en ese universo político-militante, efectivamente aleccionador y orientado hacia la consolidación de un nuevo sujeto social, las subjetividades también interpelaron y tensionaron aquellas experiencias con una mayor capacidad de agencia y de reapropiación de las normas.

Esa mirada sobre la política puede, entonces, articularse con el trabajo de Pilar Calveiro [2005] (2013), quien ha considerado que las organizaciones políticas efectivamente priorizaron en un determinado momento (el año 1974, durante el proceso de clandestinización) un modo violento de accionar por sobre otros modos políticos, de una manera tal que la lógica militarista terminó por "simplificar" la cuestión de lo político. Pero el hecho de concebir una simplificación no es homologable a negar lo político (como era el caso de la perspectiva analizada de la responsabilidad como falta político-moral). En este sentido, Calveiro propone una genealogía de la violencia en el contexto nacional del siglo XX, de la que hace uso para construir una noción distintiva y particular, atravesada por procesos históricos de disciplinamiento y de vínculos con diferentes redes de poder-saber. Así, el concepto de violencia deja de ser un instrumento que se posee y se ejercita casi unitariamente (negando otros campos de intervención), y se comprende, por el contrario, en relación a la compleja urdimbre de los procesos históricos y de sus diferentes modalidades. ${ }^{22}$

En este contexto, la violencia se percibe desde un sentido más amplio, relacional y extensivo a diferentes esferas de la vida, tensionando las interpretaciones que conciben su condición instrumental y sustituyente de la política. No se desconoce el carácter aleccionador y masculinizado de la moral de las organizaciones políticas, ni el esquema tradicional destinado a los diferentes roles sociales y de género, pero se advierten también las reapropiaciones singulares de aquellos mandatos partidarios y las transgresiones provocadas por las subjetividades sobre los códigos revolucionarios (Oberti, 2015).

En este marco, podemos afirmar que el ethos reflexivo que construye la carta de Héctor Schmucler asume la cuestión de la responsabilidad como atravesada por una dimensión ético-política. Aquí la responsabilidad no se concibe como una falta ni como un balance militante, sino como una escena reflexiva de interpelación, esto es, como una forma del dar cuenta de sí, para utilizar el concepto de Judith Butler (2005). La autora, en Dar cuenta de sí mismo (2005) y en Desposesión (2017), construye una noción de la responsabilidad que pone el foco en las condiciones sociales y normativas por las cuales los sujetos pueden dar cuenta de su obrar en el mundo. Para hacerlo, parte de una cuestión fundamental: la desposesión constitutiva que los atraviesa. 
En este paradigma, la responsabilidad toma una forma orientadora [bearing] o reflexiva, en la medida en la que asuma, exponga y enfrente las condiciones desposesivas de su constitución, es decir, en la medida en que comprenda que las normas a través de las cuales existimos no se eligen y nos exceden, pero de las cuales debemos hacernos responsables por sostenerlas "aun cuando las mantenemos abiertas y susceptibles a una confrontación, a una discusión” (Butler y Athanasiou, 2017, p. 131).

Así, hacerse responsable por ciertas acciones del pasado no implica asumir una culpa o una imputación, sino un ejercicio de reflexión que recupere la posibilidad de dar respuesta sobre ese accionar. En definitiva, un modo de actuar frente a una interpelación histórica y generacional que exige tomar determinados posicionamientos para construir legados intelectuales y políticos que no pierdan su carácter crítico y efectivamente emancipador.

La pregunta por la responsabilidad desde esta perspectiva es una inquietud fundamental y necesaria para construir una memoria crítica sobre los acontecimientos: una responsabilidad reflexiva. Así, esa demanda histórica se traduce en una interpelación cuyas respuestas explicitan un posicionamiento político-intelectual que contribuye a una discusión generacional sin deslizarse a una imputación o condena pública.

Volviendo al enunciador de Schmucler:

Se trata, y no puedo dejar de repetirme, de una obligación de responder, de un sentirse responsable que sólo corresponde a cada uno, que ningún igual puede enjuiciar, que ningún castigo puede saldar. Hablo (y el eco de Levinas es evidente) de una responsabilidad primordial, previa a todo acto, que acompaña nuestra condición humana y que deriva de la fundante responsabilidad por el otro tanto como de la libertad que nos permite decidir y sin la cual la idea misma de lo humano se desvanece (Schmucler, 2005, p. 96).

En este sentido, la responsabilidad constituye una forma de praxis que se asume públicamente e implica una lectura crítica sobre las diferentes experiencias sociales y políticas vividas. Así, el enunciador, en resonancia con los aportes de Butler, sitúa esta asunción de responsabilidad como una forma de "responder" ante una interpelación histórica donde el sujeto se reconoce como un actor capaz de revisar las narrativas sobre su propio pasado.

\section{Palabras finales}

Como mencionamos al comienzo, el problema de la responsabilidad ha sido una cuestión central en la construcción de memorias sobre las militancias de los años sesenta y setenta. A lo largo de la posdictadura, estos trabajos de memoria sobre el accionar político militante han coexistido, con mayor o menor conflicto, en el marco de las disputas por los sentidos de memoria, verdad y justicia, y han evidenciado diferentes formas de interpretar y transmitir lo ocurrido.

A lo largo del presente trabajo, se ha analizado un conjunto de cartas pertenecientes al debate No Matar (2007) referidas a este problema. Para hacerlo, se ha intentado reconstruir brevemente la genealogía de esta controversia y se ha planteado una serie analítica basada en tres formas de aproximarse al problema. Los tres modos de aproximarse al problema de la responsabilidad ponen de relieve diferentes formas de asumir la transmisión intergeneracional y el legado de los procesos políticos y emancipatorios. El debate No Matar ha sido central para discutir y, a la vez, tensionar ciertos presupuestos, discursos sociales y figuras históricas asociadas al rol y al accionar de las militancias.

Por otra parte, la controversia ha visibilizado también las múltiples dimensiones que atañen al análisis de las memorias del pasado reciente; específicamente, la imbricación fundamental entre la política, la ética y la verdad que ha acompañado al campo de estudios de la memoria desde sus orígenes. Los testimonios de Primo Levi o de Jorge Semprún, por citar dos ejemplos, son claros exponentes de esa trama multidimensional de la memoria. Por esta razón, sostenemos que la pregunta por la responsabilidad de las experiencias político- 
militantes tiene la potencia de una reflexión necesaria para consolidar un legado crítico sobre nuestros procesos de resistencias y de proyectos alternativos de poder.

\section{ReFERENCIAS}

AAVV (2007). No matar. Sobre la responsabilidad. Córdoba: Editorial Universidad Nacional de Córdoba.

Actis, M., Aldini, C., Gardella, L., Lewin, M., y Tokar, E. (2001). Ese infierno. Conversaciones de cinco mujeres sobrevivientes de la ESMA. Buenos Aires: Sudamericana.

Amado, A. (2009). La imagen justa. Cine argentino y politica (1980-2007). Buenos Aires: Colihue

Basso, M. F. (2016). Volver a entrar saltando: Memorias visuales de la segunda generación de exiliados políticos en México. Trabajo final de grado. Universidad Nacional de La Plata. Facultad de Humanidades y Ciencias de la Educación.

Basualdo, V. (2006). Derivaciones posibles de la polémica iniciada por Oscar del Barco: reflexiones para una agenda de investigación. Políticas de la memoria, 6/7. [p.25-37]

Bertoia, L., (2016). La agenda de memoria, verdad y justicia en tiempos de cambios, Aletheia, 7(13). [p. 1-18] Disponible en http://www.aletheia.fahce.unlp.edu.ar/numeros/numero-13/pdfs/Bertoia.pdf.

Brocato, C. (1985). La Argentina que quisieron. Después de la destrucción estatal y foquista; ¿qué moral civil es posible reconstruir?. Buenos Aires: Sudamericana-Planeta.

Butler, J. (2005). Dar cuenta de sí mismo. Buenos Aires: Amorrortu.

Butler, J., y Athanasiou, A. (2017). Desposesión: lo performativo en lo politico. Buenos Aires: Eterna Cadencia.

Burgos, R. (2004). Los gramscianos argentinos: cultura y politica en la experiencia de "Pasado y Presente". Buenos Aires: Siglo XXI.

Calveiro, P. (1998). Poder y desaparición. Los campos de concentración en Argentina. Buenos Aires: Colihue.

Calveiro, P. (2005) [2013]. Politica y/o violencia. Buenos Aires: Siglo XXI.

Campos, E. (2016). Cristianismo y Revolución. El origen de Montoneros. Violencia, politica y religión en los 60. Buenos Aires: EDHASA.

Carnovale, V. (2018). El legado guevarista en la izquierda armada argentina: foquismo y ética sacrificial. Politicas de la memoria, Dossier Guevarismo en América Latina, 18, 137-156.

Carnovale, V. (2014). Vencedores vencidos. Los relatos de los represores y las deudas de la memoria militante. En C. Hilb, P. J. Salazar y L. Martin [editores], Lesa humanidad. Argentina y Sudáfrica: reflexiones después del Mal [p. 75-97]. Buenos Aires: Katz.

Castillo, E. (2005). Carta enviada a La Intemperie. EnAAVV, No matar. Sobre la responsabilidad. Córdoba: UNC.

Casullo, N. (2006). Memoria y Revolución. Lucha Armada, 2(6), 32-44.

Casullo, N. (2008). Las cuestiones. Buenos Aires: FCE.

Chama, M., y Sorgentini, H. (2011). Momentos, tendencias e interrogantes de la producción académica sobre la memoria del pasado reciente argentino. Nuevo MundoMundos Nuevos [En ligne], Questions du tempsprésent, mis en ligne le 30 novembre.

Ciollaro, N. (1999). Pájaros sin luz. Testimonios de mujeres de desaparecidos. Buenos Aires: Planeta.

Crenzel, E. (2008). La Historia política del Nunca Más. Buenos Aires: Siglo XXI.

Cruz, M. (2015). Hacerse cargo. Sobre responsabilidad e identidad personal. Barcelona: Gedisa.

Diana, M. (1996). Mujeres guerrilleras. La militancia de los setenta en el testimonio de sus protagonistas femeninas. Buenos Aires: Planeta.

Del Barco, O. (2004). Carta enviada a La Intemperie. En AAVV, No Matar. Sobre la responsabilidad. Córdoba: UNC.

Feierstein, D. (2018). Los dos demonios (recargados). Buenos Aires: Marea.

Flaskamp, C. (2002). Organizaciones politico-militares. Testimonio de la luch a armada en la Argentina. Buenos Aires: Nuevos Tiempos. 
Franco, M. (2015). La “teoría de los dos demonios" en la primera etapa de la posdictadura. En C. Feld y M. Franco [directoras], Democracia, hora cero. Actores, politicas y debates en los inicios de la posdictadura. Buenos Aires: Fondo de Cultura Económica.

Gilman, C. (2003). Entre la pluma y el fúsil. Debates y dilemas del escritor revolucionario en América Latina. Buenos Aires: Siglo XXI.

Giussani, P. (1984). Montoneros. La soberbia armada. Buenos Aires: Sudamericana-Planeta.

Godoy, G., y Barbero, H. (2016). El camino de la justicia en las disputas por el sentido del pasado dictatorial. A propósito de las recientes transformaciones en la política de derechos humanos. Aletheia, 7(13). [p. 1-19]

Gouldner, A. (1979). El futuro de los intelectuales y el ascenso de la nueva clase. Madrid: Alianza.

Halbwachs, M. (2005) [1950]. La memoria colectiva. Zaragoza: Prensas Universitarias de Zaragoza.

Hilb, C. y Lutzky, D. (1984). La nueva izquierda argentina, 1960-1980. Buenos Aires: CEAL.

Hilb, C. (2014). Usos del pasado. Qué hacemos hoy con los setenta. Buenos Aires: Siglo XXI.

Hilb, C. (2001). El legado de responsabilidad. Puentes de la memoria, 2(5), 50-61.

Jelin, E. (2002). Los trabajos de la memoria. Buenos Aires: Siglo XXI.

Levín, F. (2007). Trayectorias conceptuales en torno a la noción de responsabilidad y su articulación con la historia reciente argentina. Prohistoria, XI(11), 13.

Maingueneau, D. (1996) [2010]. El enunciador encarnado. La problemática del Ethos. Versión, 24, 203-225.

Mangiantini, M. (2014). El troskismo y el debate en torno a la lucha armada. Buenos Aires: Ed. El topo blindado.

Mattini, L. (1990). Hombres y mujeres del PRT-ERP. Buenos Aires: de la Campana.

Mero, R. (1987). Contraderrota. Montoneros y la revolución perdida. Conversaciones con Juan Gelman. Buenos Aires: Editorial Contrapunto.

Oberti, A. (2015). Las Revolucionarias. Militancia, afectividad y vida cotidiana en los 70. Buenos Aires: Edhasa.

Oberti, A., y Pittaluga, R. (2006). Memorias en montaje. Buenos Aires: El cielo por asalto.

Oberti, A., y Pittaluga, R (2016). Apuntes para una discusión sobre la memoria y la política de los años 60/70 a partir de algunas intervenciones recientes. Sociohistórica, 38, [p. 1-22] Disponible en http://www.sociohistorica.fahc e.unlp.edu.ar/article/view/SHe015/7914.

Ollier, M.M. (1986). El fenómeno insurreccional y la cultura política. Argentina 1969-1973. Buenos Aires: CEAL.

Palti, E. (2008). La crítica de la razón militante. Una reflexión con motivo de La fidelidad del olvido de Blas de Santos y el "affaire del Barco. A Contra corriente, 5(2). [p. 109-126]

Pereyra, D. (2014). Memorias de un militante internacionalista. Buenos Aires: Razón y Revolución.

Pittaluga, R. (2007). Miradas sobre el pasado reciente argentino. Las escrituras en torno a la militancia setentista (1983-2005). En M. Franco y F. Levín, (2007), Historia Reciente. Perspectivas y desafíos para un campo en construcción [p. 125-152]. Buenos Aires: Paidós.

Pozzi, P. (2001). Por las sendas argentinas... El PRT-ERP. Buenos Aires: EUDEBA

Retamozo, M. (2011). Movimientos sociales, política y hegemonía en Argentina. Polis, Revista de la Universidad Bolivariana, 10(28) [p. 243-269]

Richard, N. (2007). Fracturas de la memoria. Buenos Aires: Siglo XXI.

Ricoeur, P. (1997). El concepto de responsabilidad. Ensayo de análisis semántico. En Lo justo [p. 39-68]. Madrid: Ed. Trotta.

Rot, G. (2000). Los origenes perdidos de la guerrilla en la Argentina. La historia de Jorge Masetti y el Ejército Guerrillero del Pueblo. Buenos Aires: El cielo por asalto.

Rousso, H. (2007). La trayectoria de un historiador del tiempo presente, 1975-2000. En Pérotin-Dumon (dir.), Historizar el pasado vivo en América Latina [p. 1-122]. Disponible en: http://www.historizarelpasadovivo.cl/es _contenido.php

Sadi, M. (2004). La Resistencia después del final. Buenos Aires: Nuevos Tiempos. 
Saferstein, E., y Goldentul, A. (2019). El “diálogo" como discurso emergente. La articulación de un espacio de ideas en torno a la memoria del pasado reciente en Argentina (2008-2018). Politicas de la Memoria, 19, 15-30.

Saporosi, L. (2018). La experiencia del amor en las producciones estéticas de hijos e hijas de militantes detenidos/as desaparecidos/as: La construcción de un archivo afectivo (Tesis de posgrado). Universidad Nacional de La Plata, Facultad de Humanidades y Ciencias de la Educación. Disponible en: http://www.memoria.fahce.unlp.edu.ar /tesis/te.1581/te.1581.pdf

Schmucler, H. (2005). Los relámpagos iluminan la noche. En AAVV (2007), No Matar. Sobre la responsabilidad [p. 87-98]. Córdoba: UNC.

Schmucler, H. (2007). Politica, violencia, memoria. Génesis y circulación de las ideas en la Argentina de los años sesenta y setenta, [La Plata, Ediciones Al Margen]

Sigal, S., y Verón, E. (1986) [2010]. Perón o muerte Los fundamentos discursivos del fenómeno peronista. Buenos Aires: Eudeba.

Spivak, G. (1998). ¿Puede hablar el sujeto subalterno? Orbis Tertius, 3(6), 175-235

Svampa, M. (2005). La sociedad excluyente. La Argentina bajo el signo del neoliberalismo. Buenos Aires: Taurus.

Tarcus, H. (2006). Notas para una crítica de la razón instrumental. A propósito del debate en torno a la carta de Oscar del Barco. Politicas de la memoria, 6/7, [p. 39-73]

Terán, O. (1991) [2013]. Nuestros años sesenta. Buenos Aires: Siglo XXI.

Tocho, F. (2014). Los otros “setenta": Un recorrido por la experiencia de la Tendencia Revolucionaria del Peronismo en la gobernación bonaerense [1973-1974]. Aletheia, 4(8),17.

Vázquez Villanueva, G. (2017). Solo decir verdad: memoria, responsabilidad y el esplendor del otro: los discursos sobre no matar de Oscar del Barco y Héctor Schmucler. Buenos Aires: Editorial de la Facultad de Filosofía y Letras Universidad de Buenos Aires.

Vezzetti, H. (2002). Pasado y presente. Guerra, dictadura y sociedad en la Argentina. Buenos Aires: Siglo XXI.

Vezzetti, H. (2009). Sobre la violencia revolucionaria. Buenos Aires: Siglo XXI.

Vommaro, G. (2017). La larga marcha de Cambiemos: la construcción silenciosa de un proyecto de poder. Buenos Aires: Siglo XXI.

\section{Notas}

1 Asimismo, las «poéticas testimoniales» y/o las «figuraciones de la memoria» (Amado, 2009, Basso, 2016; Richard, 2007) de la generación de hijos e hijas de militantes irrumpieron en la escena pública de la memoria e instalaron, con un fuerte acento en los afectos (Saporosi, 2018), una lectura singular sobre sus identidades y biografías, al mismo tiempo que contribuyeron a revisar críticamente las figuras e idearios revolucionarios de sus padres y madres y sus lazos con las organizaciones políticas.

2 Como sugieren diversos autores (Vommaro, 2017; Retamozo, 2011), los conflictos políticos y sociales generados en relación con la Resolución 125 a partir del año 2008 constituyeron un momento crucial para comprender la reorganización y reagrupamiento de las fuerzas políticas tanto en el arco oficialista y como en los sectores de la oposición al gobierno de Cristina Fernández Kirchner. Estos conflictos contribuyeron a que se generaran las condiciones de posibilidad para la emergencia de una nueva escena de disputas por los sentidos del pasado reciente, tensionando lo que se consideraba una «memoria oficial» (Carnovale, 2014) impulsada por el administración de Néstor Kirchner y Cristina Fernández de Kirchner.

3 El Ejército Guerrillero del Pueblo (EGP), impulsado por el Che Guevara y dirigido territorialmente por Jorge Masetti, desarrolló su actividad durante los años 1963 y 1964 en la provincia de Salta, con el objetivo de crear un foco guerrillero en el norte argentino. El grupo estuvo conformado por no más de 20 personas y no llegó a producir ningún operativo de relevancia. En marzo de 1964, la gendarmería nacional logró desarticular la organización del grupo guerrillero y varios de sus integrantes fueron trasladados a Orán. Allí estuvieron hasta junio del 64 y luego fueron llevados a la cárcel de Tucumán.

4 Estos enfoques sobre la responsabilidad se constituyen a partir de un conjunto de paradigmas teóricos y epistemológicos sobre el problema y abarcan una serie más amplia de ejercicios de memoria referidos a la experiencia militante de aquellos años. Estas series trascienden al debate No matar y se extienden en diferentes trabajos publicados durante 
los años de la posdictadura. Incluso, a partir de su análisis, pueden observarse diferentes variantes en la forma de asumir la responsabilidad dentro de los mismos enfoques propuestos. A los fines del presente trabajo, como se dijo, nos circunscribimos en el debate No matar y hablamos de aproximaciones en la medida en que se toman ciertos elementos relevantes de esos enfoques para analizar las cartas seleccionadas del debate.

5 Este encuentro ha sido narrado por Raúl Burgos (2004) y por Gabriel Rot (2000) y analizado críticamente por Vázquez Villanueva (2016) quien ha revisado ciertos planteos de Burgos y Rot, específicamente aquellos que han puesto el acento en el «carácter premeditado» del encuentro entre el EGP y los miembros de Pasado y Presente. Según Vázquez Villanueva, «los testimonios de del Barco, Aricó y Schmucler, señalan todo lo contrario» (p. 28) y destaca, por un lado, su carácter fortuito (Aricó) y, por el otro, el «grave error» (del Barco) de haber contribuido a que muchos militantes se acercaran a la experiencia guerrillera (p. 29).

6 Para un análisis de estas conceptualizaciones sobre la lucha armada, ver Carnovale (2018), Mangiantini (2014), Pozzi (2001), Campos (2016).

7 La idea del ethos discursivo, según Maingueneau (1996), permite analizar la imagen que los enunciadores construyen de sí, a través de las dimensiones del tono o voz, de carácter y/o del cuerpo. La idea del ethos conmocionado que construye la carta de Del Barco puede articularse con la propuesta de Graciana Vázquez Villanueva de considerar esa imagen como un ethos parresiasta (2016). A nuestro entender, y sin ser contradictoria, la idea del ethos conmocionado resulta más amplia para atender a nuestros objetivos específicos.

8 Si bien excede a los fines del presente trabajo, resulta pertinente señalar aquí que esta aproximación se articula con el paradigma de Karl Jaspers, en torno al problema de la culpa y sus cuatro formas (criminal, política, moral y metafísica), y con los aportes filosófico-religiosos de Immanuel Levinas, respecto a la responsabilidad como una forma de atender «lo infinito del Otro» expresada en la «epifanía del rostro». La obra de Jaspers ha sido recuperada por algunos autores, como Hugo Vezzetti (2002), para referir al caso argentino. Las diferentes reapropiaciones de estos (y otros) paradigmas para pensar el pasado reciente argentino permiten que estos aportes teórico-epistemológicos contribuyan a conformar el enfoque de la responsabilidad como falta político-moral.

9 Para el presente trabajo utilizamos la versión publicada en la compilación Usos del pasado. Quéhacemos hoy con los setenta. (2014).

10 Este punto de discusión es retomado en el «El legado de responsabilidad» (2001): la autora ha utilizado el concepto de captura para referir al «proceso por el cual los ideales igualitarios y libertarios de la mayoría de aquellos que adhirieron a los movimientos políticos contestatarios hacia fines de los sesenta y principios de los setenta quedaron subordinados al discurso y la práctica militarista, jerárquica, antidemocrática y antipolítica de las organizaciones a las que se unieron» (Hilb, 2001 [2014], p. 32). Esta interpretación puede articularse con el planteo de otros/as autores/as, como Hugo Vezzetti (2009), Vicente Palermo (2002) o Vera Carnovale (2014).

11 Resulta pertinente señalar críticamente la idea de reducir un conjunto vasto, complejo y heterogéneo de experiencias militantes bajo la noción de militancia revolucionaria. Como sugieren Oberti y Pittaluga (2016), «la imprecisión de las denominaciones es parte de una modalidad enunciativa, donde «nueva izquierda», «fuerza insurreccional»o «militancia revolucionaria» son intercambiables con organización político-militar, con guerrilla, con foquismo o, aun, con terrorismo». (Oberti y Pittaluga, 2016, p. 2).

12 «o matarás al hombre porque todo hombre es sagrado y cada hombre es todos los hombres» (Oscar del Barco, 2004, p. 36).

13 Para este punto, ver Hilb (2014) y Carnovale (2014).

14 Como se mencionó al comienzo, este tipo de producciones se inscriben en una genealogía de revisiones críticas que pueden rastrearse en las (otras) cartas de Rodolfo Walsh enviadas a la Conducción Nacional de Montoneros hacia fines de 1976 y principios de 1977, o en las conversaciones entre Juan Gelman y Roberto Mero publicadas en 1987, o bien, en la reconstrucción crítica de Luis Mattini sobre el PRT-ERP (1990), entre otros. En efecto, estos ejercicios de memoria construyen sus argumentaciones poniendo el foco del análisis en la historización de las organizaciones político militares y en un vínculo teórico-político particular sobre el uso de la violencia y la acción política.

15 Para profundizar en este planteo resultan fundamentales las contribuciones de Oberti (2015), Chama y Sorgentini (2011), Mangianitini (2014), Tocho (2014), entre otros. Desde diversas perspectivas, estos trabajos se han orientado a complejizar las interpretaciones sobre las experiencias militantes, intentando evitar reduccionismos y simplificaciones.

16 Como explica Marisa Sadi (2004) para la región de Capital Federal y Buenos Aires, la JUP -espacio de militancia del autor, pero en la ciudad de Rosario- confluyó en la organización Montoneros y, hasta 1978, se mantuvo activa y relativamente autónoma de las decisiones de las cúpulas de Montoneros.

17 En este punto, resulta pertinente mencionar la perspectiva de Horacio Tarcus, en relación al mandato «no matarás». Para el autor, referir únicamente a la dimensión religiosa del mandato resulta ser parcial puesto que ignora una cuestión fundamental, también postulada por Oscar del Barco, asociada a la imposibilidad de sostener dicho principio como un fundamento último para la construcción de una comunidad. El hecho de advertir esta imposibilidad, según Tarcus, le 
da al argumento de Del Barco un carácter histórico que posiciona el problema de la violencia en una perspectiva éticohumanista. Resulta interesante, asimismo, poner en tensión estas consideraciones recuperando la mirada de Elías Palti.

18 En esta misma línea se orientan los ejercicios de memoria de Carlos Flaskamp (2002), de Marisa Sadi (2004) y de Daniel Pereyra (2014).

19 En esta misma línea, Florencia Levín (2007) ha sugerido que la aproximación al concepto de la responsabilidad como falta (desarrollado en el apartado anterior) ha excedido ampliamente sus reapropiaciones en el campo de estudios del pasado reciente argentino. Y, sin abandonar las importantes implicancias de esta perspectiva, la autora recupera el concepto de acción en sus diferentes tradiciones para pensar la responsabilidad desde otra corriente analítica. Sugiere entonces que la cuestión clave del concepto está en su constitución como una capacidad para actuar, y, por tanto, en su articulación con una determinada mirada ética de los acciones

20 Se hacen menciones a textos de Benjamin, de la Odisea y a la obra El Grito de Münch, o a la obra de Immanuel Levinas.

21 Esta idea se inspira libremente en los planteos de Gayatri Spivak en relación al rol y a la respuesta de los intelectuales solidarios frente a la voz de la alter(n)idad: dejarse atravesar frente a ella. Para profundizar, ver Spivak (1998).

22 Las perspectivas de Alejandra Oberti y de Roberto Pittaluga (2006) pueden dialogar críticamente con esta línea interpretativa y contribuyen a comprender la complejidad del vínculo entre moral revolucionaria y subjetividades militantes. En esta discusión han complejizado el planteo de Calveiro en un doble sentido: por un lado, han revisado la distinción entre «prácticas políticas» $\mathrm{y}$ «prácticas militaristas» en las organizaciones, buscando reponer la «valoración epocal» de esas acciones en un determinado contexto histórico. La segunda revisión refiere a la necesidad de considerar analíticamente la politización de los movimientos de masas y su consecuente inserción en las agrupaciones armadas. Para profundizar, ver Oberti y Pittaluga (2006). 